\title{
The True Significance of the EFSF Downgrade
}

It may come as a surprise for many observers, but the recent rating downgrades of several European countries and the European Financial Stability Facility (EFSF) by Standard and Poor's has not resulted in major reactions in financial markets. Several countries as well as the EFSF were able to successfully complete their first post-downgrade auctions and enjoyed sufficient demand at relatively low interest rates. This development may be even more surprising when one takes into account the fact that political resistance against an increase in guarantees in the remaining four AAA countries is strong and that the ongoing discussions on the leveraging of the EFSF have not resulted in any solution yet - and it remains unclear whether any meaningful and effective solution can be found.

So the question arises as to whether these ratings are no longer important for investors in their portfolio allocation decisions. However, this is unlikely; rather, it is a combination of various factors that helped here to contain any widespread reactions. First, so far only one of the three major rating agencies has downgraded the EFSF. Second, the downgrading decision had been expected for quite some time and had thus already been incorporated into prices. Therefore the political criticism regarding this downgrading decision seems to be misguided.

Does this mean that we do not need to discuss the role of rating agencies in general and the need for a European rating agency? Certainly not. Rating agencies played an unfortunate role in the building up of the 2007-08 financial crisis, and their business models show obvious weaknesses and conflicts of interest. So what could a European rating agency do here? I would hope that the political rationale behind advocating for the creation of such an agency is not the implicit expectation of more benign ratings for European issuers. In this case, history would only repeat itself and the foundation for the next financial crisis would be laid. Rather, the creation of a new major player in the rating industry could increase competition and strengthen market dynamics. Even more importantly, the business model of such a new rating agency should be designed differently so as to overcome the conflicts of interest and agency problems for which sufficient empirical academic evidence exists. More practically, should such a rating agency have come up with different ratings for many of the structured investment vehicles that were at the heart of the 2007-08 financial crisis? Certainly. Should such a rating agency have come up with different ratings for European countries in the current sovereign debt crisis? Probably not. Nobody can dispute that the public debt in Greece is in a dire situation. Nor can anyone dispute that the reform efforts in Italy have only become credible with the new Monti government. Finally, nobody can dispute that the reforms in France are coming too late. Should such a rating agency have come up with different ratings for the United States? Maybe. But it is important to keep in mind here that the US government enjoys the benefit of being able to issue its bonds in a currency controlled by its own central bank, with the Fed being the lender of last resort, in contrast to countries in the eurozone.

The more fundamental question is whether the EFSF's credit rating is of first-order importance in the current situation. Several observations lead one to think that it is not. First, even if the interest rates of the EFSF were to rise moderately due to the rating downgrade, the EFSF could still maintain its role and lend to countries in need. Second, the removal of the requirement to maintain a AAA rating may even increase the effective 
lending volume. Third, the EFSF will soon be replaced by the European Stability Mechanism (ESM), which will not be built solely upon guarantees but will also receive equity injections from the eurozone countries. These are all important reasons to believe that the rating for the EFSF is less important than often argued, and they offer further explanation for the calm reaction in financial markets to its downgrading.

There is an even more important reason. Over the last three years, the European Central Bank (ECB) has stretched its mandate to the extreme. In reaction to the substantial frictions in the interbank lending market and the continued unwillingness of banks to lend to each other, it has implemented a number of far-reaching policy changes. First, it has lowered the rating requirements for securities that can be used as collateral in its open market operations and has in particular removed minimum ratings for sovereign bonds from several peripheral countries. Second, it has practiced a full allotment policy that allows banks to receive as much liquidity as they can provide collaterisable assets for. More recently, the ECB has also conducted liquidity injections with a maturity of three years, thus providing the banking sector with much needed liquidity - and the opportunity to buy more sovereign bonds. It can be argued that the recent success of bond auctions in Italy and Spain, for example, can to a large extent be attributed to this ECB policy change, which allows banks to buy sovereign bonds in these and other countries and use these bonds as collateral to obtain liquidity from the ECB, thus enjoying a significant interest rate arbitrage. So it seems that the ECB rather than the EFSF has taken over the role of the rescuer. The fact that the ECB has recently slowed down its outright purchases of sovereign debt in its securities market programme may help to alleviate concerns in many core countries about it overstepping its mandate, but the other key policy changes remain in place.

Governments throughout the eurozone have agreed on substantial reforms to reduce government debt and - maybe even more importantly - to restore competitiveness. Nonetheless, these reforms need time to take effect, and it is not clear whether there will be enough time. If not, it is increasingly being argued that, in their current design, the EFSF and ESM alone will be neither fast enough nor sufficient to deal with the potentially arising challenges. The ECB thus plays a major role in many of the currently discussed proposals: the EFSF and ESM may receive a banking license with recourse to the ECB open market operations, they may receive loans from the ECB, or the ECB may provide loans to the International Monetary Fund (IMF), which would then give loans to the euro countries in need. In sum, the ECB is at the centre of the efforts to deal with a potential shortage of time and money, even with rising inflation concerns and the substantially increasing risks in its balance sheet. This may be another way to interpret the calm reactions by financial markets to the EFSF downgrade: markets are simply paying more attention to the ECB decisions.

What to make of this? It is important to stress the advantage the EFSF and ESM as well as the IMF have over the ECB, namely the conditionalities with which these institutions can provide funding to debtors in need. These conditionalities, in the form of a quid pro quo of funding in exchange for reforms, are of crucial importance for an effective and sustainable solution to the sovereign debt crisis in the eurozone. Many of the weaknesses and inefficiencies in the peripheral eurozone countries cannot be addressed by more liquidity alone; instead they require long-term help and support which can only be secured by multilateral political decisions. We thus need a strong EFSF and ESM, plus the help of the IMF. The calm financial market reactions to the EFSF downgrade should not mask this need. 